\title{
0 uso de geotecnologias na elaboração de mapas de ruído
}

\section{The use of geotechnologies in the noise mapping}

\author{
Évely Mara Scariot \\ Engenheira Ambiental pela Universidade Federal de Mato Grosso do Sul (UFMS) - Campo Grande (MS), Brasil.
}

\begin{abstract}
Antonio Conceição Paranhos Filho
Geólogo. Doutor em Geologia Ambiental pela Universidade Federal do Paraná (UFPR) - Curitiba (PR), Brasil. Professor Associado da UFMS - Campo Grande (MS), Brasil.

\section{Thais Gisele Torres}

Engenheira Ambiental. Mestre em Tecnologias Ambientais pela UFMS - Campo Grande (MS), Brasil. Assessor em Ciências da Terra do Ministério Público do Estado de Mato Grosso do Sul - Campo Grande (MS), Brasil.
\end{abstract}

\section{Ana Cristina Budib Victório}

Tecnóloga em Processamento de Dados. Cordenadora do Grupo de Informática e Geoprocessamento na Secretaria Municipal de Meio Ambiente e Desenvolvimento Urbano da Prefeitura Municipal de Campo Grande - Campo Grande (MS), Brasil.

\section{Resumo}

A elaboração de mapas de ruído com o apoio das geotecnologias é uma poderosa ferramenta para visualização e compreensão do comportamento do ruído em determinada área. Nesta pesquisa avaliaram-se os níveis de pressão sonora em uma região de aproximadamente 18 ha, composta por indústrias, residências, criação de animais e uma avenida movimentada no entorno do município de Campo Grande (MS). Efetuaram-se análises semivariográficas das amostras e os mapas de ruído foram desenvolvidos utilizando-se krigagem, que se mostrou adequada, desde que os dados coletados fossem representativos e os pontos de amostragem coerentes com a situação que se queria avaliar. Os mapas de ruído permitiram identificar as regiões mais críticas, as fontes e suas respectivas áreas de influência, além de verificar onde são ultrapassados os limites normativos de pressão sonora.

Palavras-chave: medição de ruído; impacto ambiental; sistemas de informação geográfica; poluição sonora.

\section{Abstract}

Geotechnologies application in noise mapping consists in a powerful tool to visualize and understand the sound distribution in a specific area. This research was done at the city of Campo Grande, Mato Grosso do Sul, Brazil, in an area of approximately 18 ha, where there are industries, residences, animal breeding and an avenue. Sound level pressures were explored, semivariografic analysis were done and noise maps were developed using kriging, that demonstrated to be appropriated, since that the collected data were representative and the sampling points coherent with the situation that needed to be evaluated. The noise maps permitted to identify the most critical regions, the sources and their influence areas, as verify where the normative limit values for sound pressure exceed.

Keywords: noise measurement; environmental impact; geographic information systems; sound contamination.

\section{Introdução}

Os sons, embora muitas vezes passem despercebidos, estão sempre presentes, sejam eles produzidos pelas invenções humanas, ou do meio natural, como o barulho do vento, os cantos dos pássaros, bem como a própria respiração (SHAFER, 2001). O advento da industrialização, o crescimento das cidades e a ampliação da frota de veículos contribuíram para o aumento da exposição a barulhos desagradáveis e de intensidades elevadas, que podem provocar desde um pequeno desconforto até a perda auditiva. Isso gerou a necessidade de criação de normas, voltadas a empresas e à comunidade, com a finalidade de minimizar ou eliminar os problemas e conflitos causados pela emissão de ruídos.

Ruído é definido pela maioria dos autores como um som indesejável, desagradável, que interfere no que se quer ouvir (GERGES, 2000; MOTA, 2006; SHAFER, 2000). Astete et al. (1989) comentam 
que, no caso da acústica, ruído é um fenômeno físico que indica uma mistura de sons cujas frequências não seguem nenhuma lei precisa. Por sua vez, o termo som é definido por Derisio (2000) como qualquer variação de pressão (no ar, água ou algum outro meio) que o ouvido humano possa detectar.

Percebe-se que a definição de ruído é bastante subjetiva, visto que um som pode, ao mesmo tempo, ser agradável a um indivíduo e perturbador para outro (DAVIS; CORNWELL, 1998; SHAFER, 2001). Esta é, de acordo com Davis e Cornwell (1998), uma das razões pelas quais a poluição sonora não é tão comentada. Além do fato de apresentar rápido decaimento, não permanecendo constante no espaço e nem no tempo, ao contrário de outras formas de poluição. Sem contar que os efeitos psicológicos e fisiológicos provenientes da exposição ao ruído aparecem gradualmente, sendo difícil associar causa ao efeito (DAVIS; CORNWELL, 1998; MOTA, 2006).

O ruído é um dos agentes físicos nocivos mais comuns encontrados em ambientes de trabalho (LEAO; DIAS, 2010). Conduz à fadiga dos operários, causando redução da produção e provocando acidentes (MOTA, 2006; STELLMAN; DAUM, 1975). Os trabalhadores fatigados prestam menos atenção, recebem novas informações visuais mais lentamente, necessitam de mais tempo para pensar, e apresentam diminuição de motivação e desempenho (STELLMAN; DAUM, 1975). Contudo, Davis e Cornwell (1998) afirmam que é mais provável que o ruído reduza a acurácia da tarefa do que diminua a total quantidade de trabalho. Em uma linha de produção, por exemplo, não há como parar; a quantidade produzida será a mesma, mas a qualidade da operação pode decair. Tarefas mais complexas, que exigem mais concentração, são as mais afetadas pelo ruído (DAVIS; CORNWELL, 1998).

A elaboração de mapas de ruído de indústrias por meio de modelação em computador é uma ferramenta poderosa para a gestão ambiental de unidades industriais, permitindo evidenciar o cumprimento ou não de determinados níveis de ruído na envolvente, para efeitos de certificação ambiental, por exemplo, bem como definir planos de ação de redução de ruído (SANTOS; VALÉRIO, 2004). Os resultados são normalmente apresentados sob a forma de linhas isofônicas e/ou manchas coloridas, representando as áreas cujo nível de ruído se situa numa dada gama de valores (SANTOS; VALADO, 2004).

Nesse contexto, as geotecnologias dão apoio à espacialização dos níveis sonoros por meio de imagens aéreas, Sistemas de Informações Geográficas (SIGs), ferramentas geoestatísticas e demais tecnologias de tratamento e manipulação de dados geográficos.

Esta pesquisa teve como principal objetivo avaliar os níveis de pressão sonora em uma área de aproximadamente 18 ha, situada no município de Campo Grande (MS). Na área de estudo encontram-se instaladas duas indústrias - uma de produtos plásticos e outra de tintas e vernizes. Há também criação de animais, residências e uma avenida movimentada no entorno, que interferem na paisagem sonora local.
Buscou-se identificar e mensurar as principais fontes de poluição sonora na área de estudo, desenvolver mapas de ruído com o apoio de geotecnologias e, então, comparar os níveis de pressão sonora com os limites estabelecidos pelos dispositivos legais em vigor, visando o conforto da comunidade e a saúde dos trabalhadores.

\section{Metodologia}

A pesquisa foi realizada no município de Campo Grande (MS), em uma propriedade privada, dentro da qual estão instaladas duas indústrias, uma de produtos plásticos e outra de tintas e vernizes, englobando também suas proximidades. Foram omitidos neste trabalho os nomes das empresas, bem como suas reais coordenadas, para preservar sua privacidade.

Havia-se prévio conhecimento acerca do ruído em alguns pontos internos das indústrias, provenientes de trabalhos preventivos regularmente feitos nas empresas, visando à saúde do trabalhador. Mas desconhecia-se sua distribuição ao longo do espaço físico, principalmente nas áreas abertas.

Primeiramente, foram levantados dados das empresas, como planta baixa e horários de funcionamento dos setores, para definir os locais de amostragem e o período de coleta de dados. Visitas prévias foram necessárias para conhecer o processo produtivo e realizar algumas medições de ruído, de modo a ter noção da intensidade dos sons presentes. Conversou-se com vizinhos sobre a pesquisa que estava sendo realizada, com o intuito de pedir permissão para fazer avaliações no local e conhecer os hábitos dos moradores.

Para verificar a distribuição espacial dos sons locais, foram realizadas avaliações de ruído em diversos pontos no espaço estudado. Os critérios observados na escolha desses pontos foram: existência de uma fonte de ruído (máquinas), proximidade de barreiras artificiais (muros, paredes), facilidade de identificar o local amostrado nas fotografias aéreas disponíveis (georreferenciadas e com resolução espacial de $16 \mathrm{~cm}$ ), delimitação da área de estudo por meio de pontos mais distantes das fontes, e criação de uma malha de pontos representativa.

Determinaram-se as coordenadas de cada ponto amostrado a partir de fotografias aéreas ortorretificadas e georreferenciadas, cedidas pela Prefeitura para a realização deste estudo. Essas imagens compõem o Sistema Geomorena e foram obtidas entre o período de novembro de 2007 e julho de 2008.

As medições de ruído seguiram os procedimentos estabelecidos na NBR 10.151/2000 (ABNT, 2000) e foram feitas com um medidor integrador de nível sonoro, modelo Solo, classe 2, da marca 01dB. O mesmo e seu calibrador possuem certificados de calibração da Rede Brasileira de Calibração (RBC), acreditados pelo Instituto Nacional de Metrologia, Normalização e Qualidade Industrial (INMETRO). Ao mesmo tempo em que eram avaliados os níveis de pressão sonora, descreveram-se os sons percebidos e suas respectivas fontes. 
Em geral, os sons nas indústrias avaliadas são contínuos, com intensidade que não varia consideravelmente com o tempo. Portanto, nessas situações, o período integralizado pelo medidor de nível sonoro foi em torno de um minuto, estando o mesmo programado para registrar valores a cada segundo. Nos pontos em que havia significativa variação de ruído, principalmente próximo à rodovia, na qual a intensidade do som depende do fluxo e porte dos veículos em trânsito, o tempo de coleta de dados foi mais longo.

Neste trabalho, caracterizaram-se duas situações distintas, que serão aqui tratadas como "A" e "B". A primeira (A) representa um dia de trabalho normal e a segunda (B) um fim de semana, sem a interferência das indústrias. Em ambos avaliou-se apenas o período diurno.

Posteriormente, os dados obtidos em campo foram transferidos para um computador e organizados em forma de tabelas, a partir das quais se extraíram as informações necessárias para as demais etapas do trabalho. Utilizaram-se os valores de $\mathrm{L}_{\mathrm{eq}}$ (nível sonoro equivalente), expresso em $\mathrm{dB}(\mathrm{A})$, que corresponde ao nível sonoro médio integrado durante o período de cada medição.

Procedeu-se à análise da distribuição espacial dos níveis de pressão sonora por meio de geoestatística. Foram construídos semivariogramas e ajustados aos modelos teóricos: esférico, exponencial e gaussiano, por meio do software Surfer 8 (GOLDEN SOFTWARE, 2002).

Com os semivariogramas prontos, geraram-se mapas de contorno pelo método da krigagem para cada modelo analisado, além do modelo padrão do Surfer 8 (GOLDEN SOFTWARE, 2002), que é linear. Com base nos resultados e na comparação deles com a realidade percebida em campo, escolheram-se os modelos que melhor representaram a distribuição espacial do ruído na área de estudo.
Por fim, foram comparados os níveis de pressão sonora obtidos aos limites estabelecidos pelos dispositivos legais em vigor, voltados tanto ao conforto da comunidade quanto à saúde do trabalhador.

\section{Resultados e Discussão}

Para analisar a situação A, foram escolhidos 87 pontos de amostragem, irregularmente distribuídos na área de estudo. Menor quantidade de pontos foi avaliada na situação $\mathrm{B}$, devido à menor variação sonora percebida em campo (Figura 1).

Ambas as situações (A e B) apresentaram anisotropia, que pode ser observada a partir dos semivariogramas experimentais direcionais das duas amostras, representados, respectivamente, nas Figuras 2 e 3 .

A forma do semivariograma na direção $90^{\circ}$ (Norte-Sul) para a situação A (Figura 2), em que reduzidas distâncias apresentaram semivariância mais elevada do que grandes distâncias, pode ser explicada pelas próprias dimensões dos barracões das indústrias, em formato retangular, onde as maiores paredes estão orientadas quase que perpendicularmente à direção Norte-Sul, agindo como barreiras sonoras concentradas e causando maior variabilidade do Leq em pontos mais próximos.

Em B (Figura 3), a variável $\mathrm{L}_{\text {eq }}$ variou menos com a distância na direção Norte-Sul e mais na direção Leste-Oeste devido ao fato de o fluxo de veículos na avenida - única fonte de ruído detectada na presente situação - ocorrer aproximadamente na direção Norte-Sul, provocando a gradativa atenuação do ruído com a distância perpendicularmente à direção da via.

Posteriormente, aplicaram-se os modelos teóricos esférico, exponencial e gaussiano. Todos foram capazes de representar as curvas

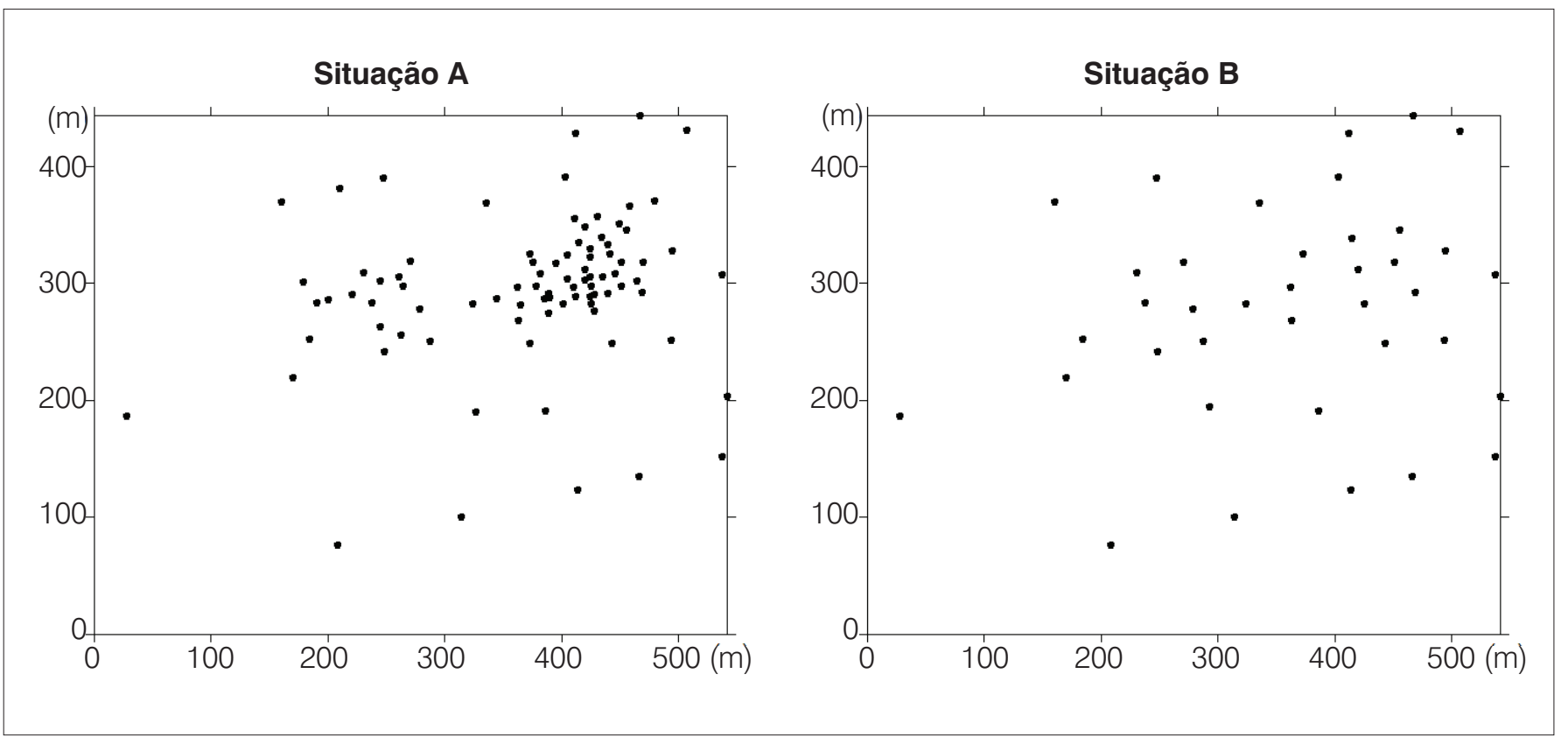

Figura 1 - Pontos de medição de ruído em um dia típico de trabalho (situação A) e em um fim de semana (situação B). 


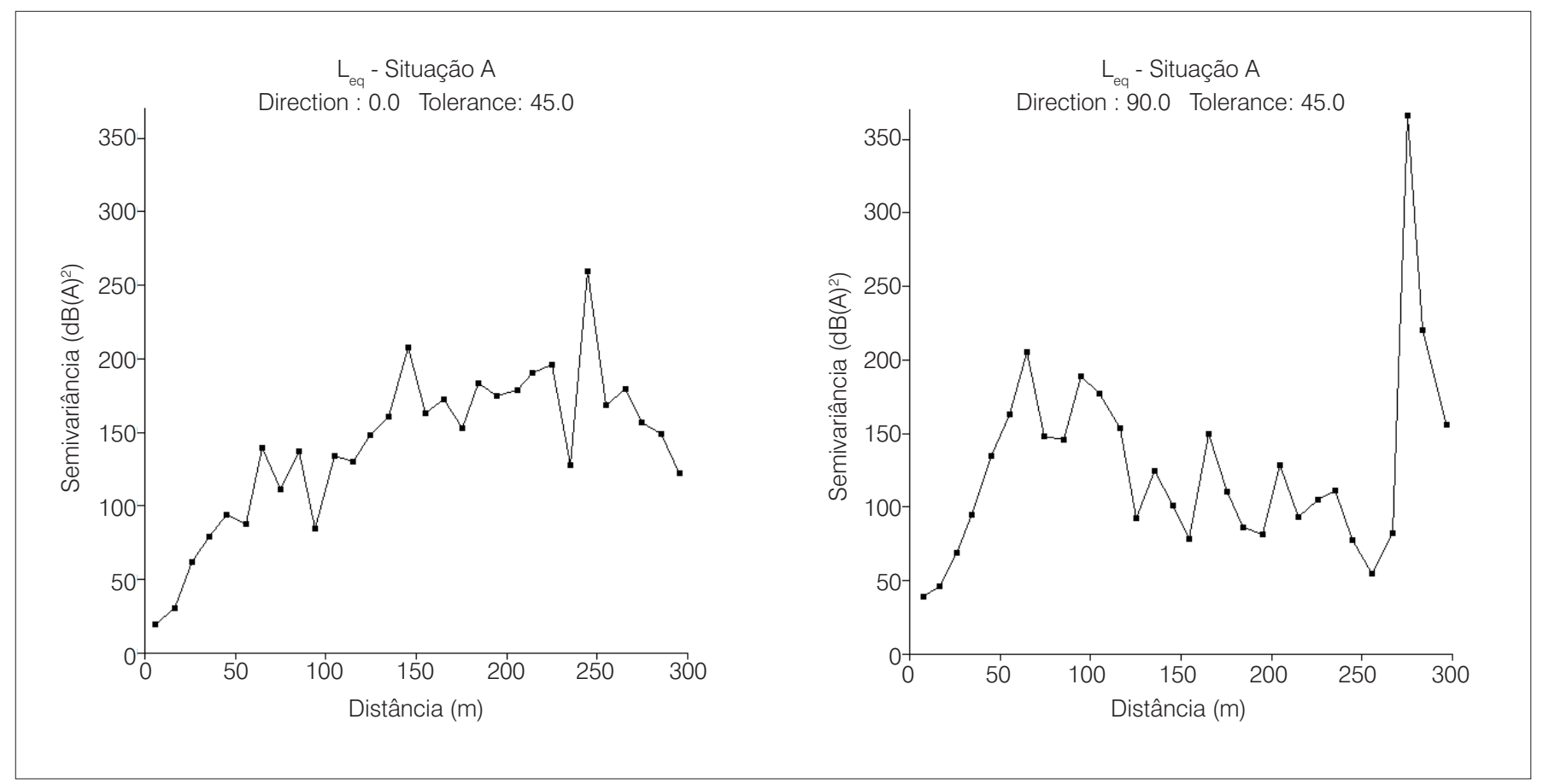

Figura 2 - Semivariogramas experimentais direcionais para a amostra A.
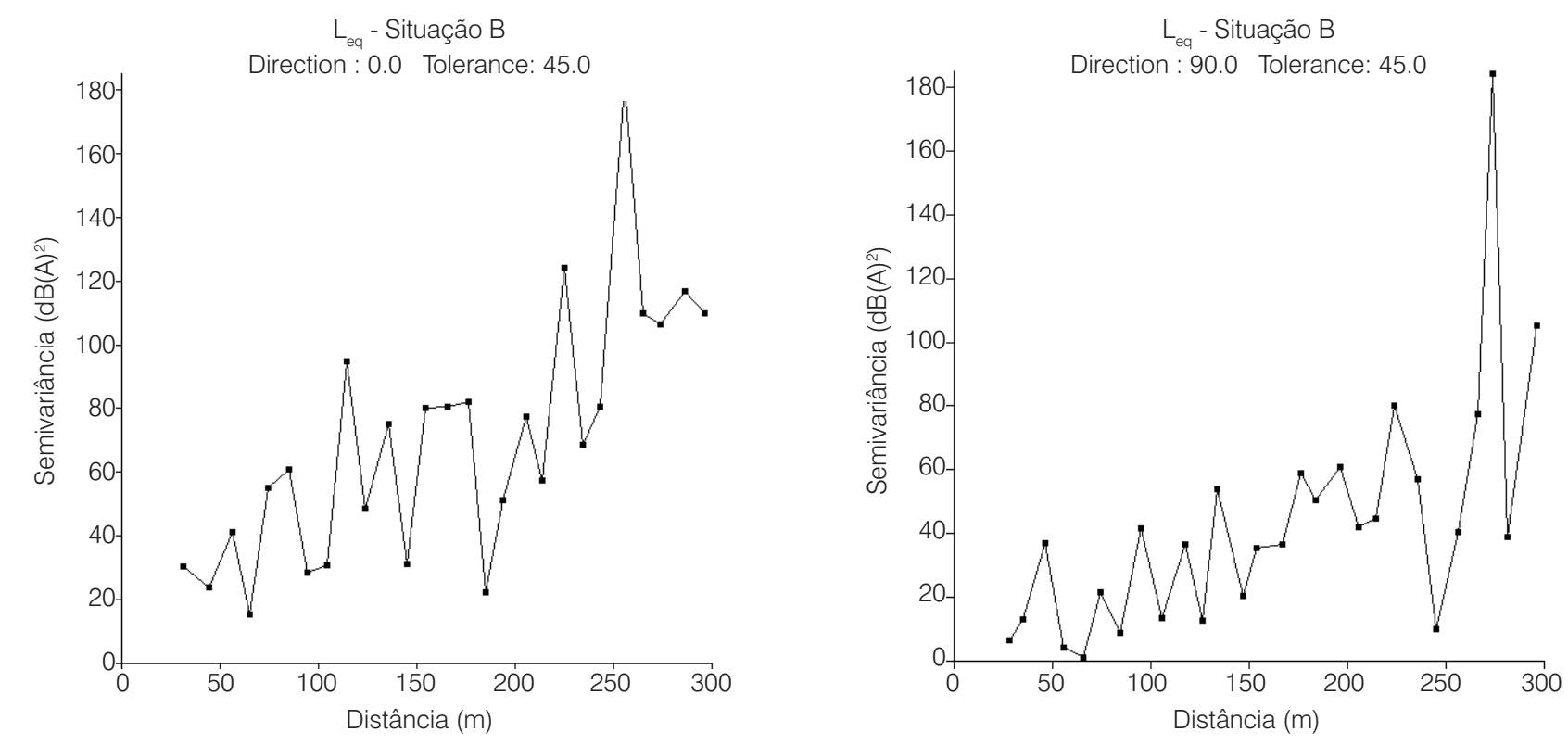

Figura 3 - Semivariogramas experimentais direcionais para a amostra B.

dos semivariogramas experimentais. Porém, após as modelagens, analisou-se a validação cruzada para cada modelo, confrontando os valores originais e os estimados. Para a situação A, o modelo que, em geral, apresentou menos resíduos foi o padrão do software utilizado, e em seguida, o modelo exponencial. Contudo, Landim (2003) reforça que a validação cruzada não prova que o modelo escolhido é o mais correto, mas sim que não é inteiramente incorreto. Comenta, ainda, que a melhor verificação é aquela resultante do confronto entre os valores estimados e a realidade de campo.

Com base nessa afirmação, dentre as modelagens analisadas (Figura 4), verificou-se que a linear padrão do software conseguiu representar melhor a influência do fluxo de veículos na avenida existente na área estudada, porque interpretou essa região como uma fonte "linear", ao contrário dos outros modelos, que consideraram 
os pontos amostrados nas margens da avenida como fontes pontuais. Deve-se levar em consideração que, apesar de cada veículo que transita na avenida ser uma fonte móvel, sempre há fluxo de veículos na via, que acabam a mantendo como uma fonte de ruído em linha.

Focos pontuais de ruído, em meios mais uniformes, sem predominância de barreiras acústicas, podem ser mais bem representados pelos modelos ajustados ao semivariograma. Mesmo assim, o modelo linear padrão foi capaz de definir os focos de maior ruído e propagá-los em contornos curvos, devido à densidade de pontos ter sido maior nessas regiões, por existirem várias barreiras artificiais que provocam mais variabilidade em pequenas distâncias.

Conforme a Figura 4, os quatro modelos foram capazes de indicar a localização dos focos de maior ruído, pois praticamente coincidiram em todos os modelos, demonstrando sua aplicabilidade para detectar as áreas mais críticas de poluição sonora. No entanto, nenhum deles apresentou resultados bastante confiáveis fora dos limites das propriedades analisadas, ou seja, além da malha de pontos definida. Amostragens feitas nas coordenadas $(0,0)$ e $(0,440)$ do mapa, mais distantes de onde as indústrias estão instaladas, poderiam fornecer resultados mais confiáveis para essas áreas, visto que o método da krigagem geralmente não consegue extrapolar tão bem quanto interpola.

Nas regiões onde a densidade de pontos amostrados foi menor, por não ter barreiras artificiais e apresentar predomínio de pastagem, o modelo linear apresentou significativa divergência com os demais modelos. Contudo, aproximou-se do esperado, visto que na redondeza (fundos da propriedade, esquerda dos mapas) não há ocupação antrópica próxima que possa interferir com valores mais altos de ruído, além de existir muro alto na divisa.

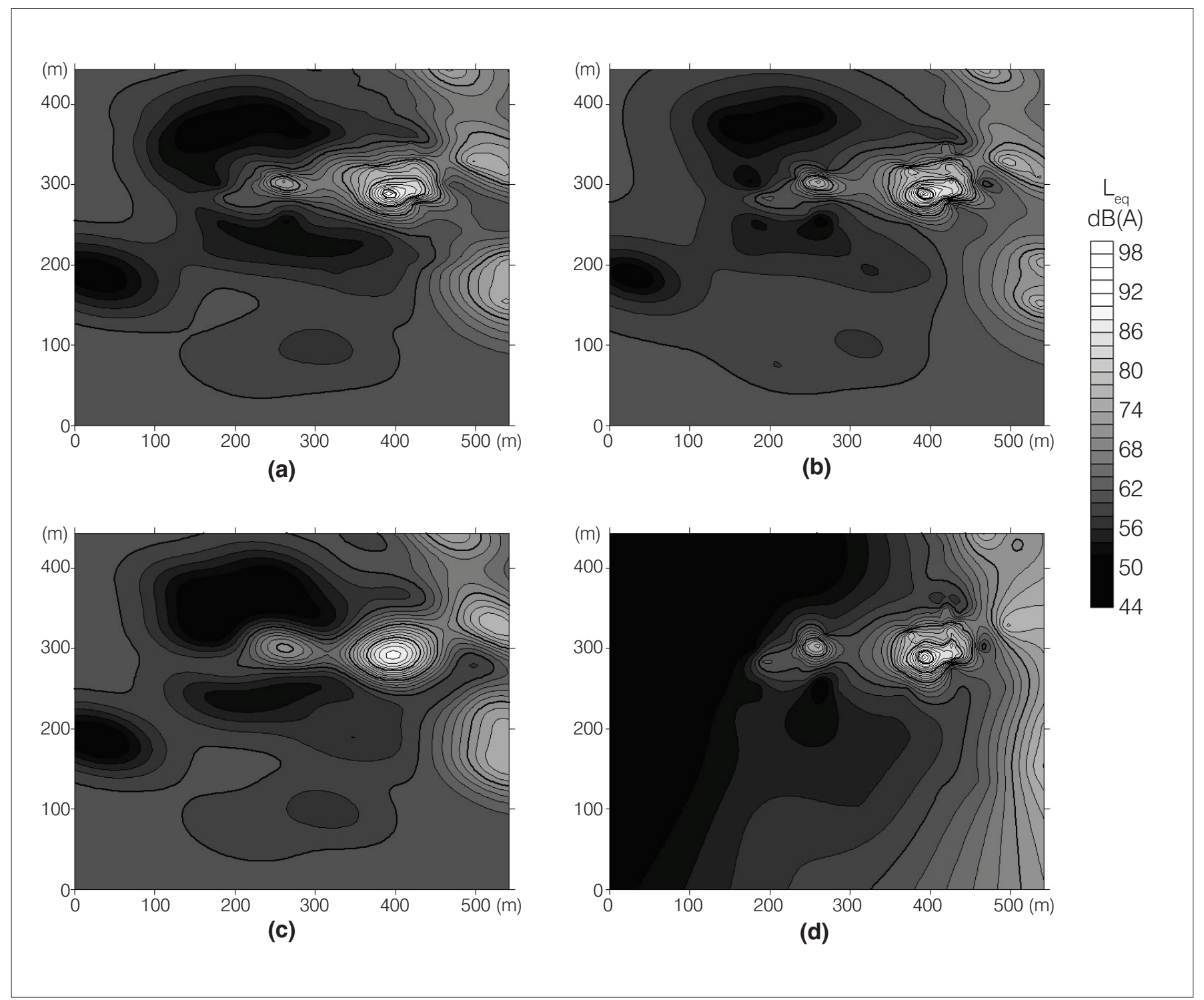

Figura 4 - Mapas de contorno da situação A gerados a partir dos quatro modelos analisados: esférico (a), exponencial (b), gaussiano (c) e linear padrão (d). 


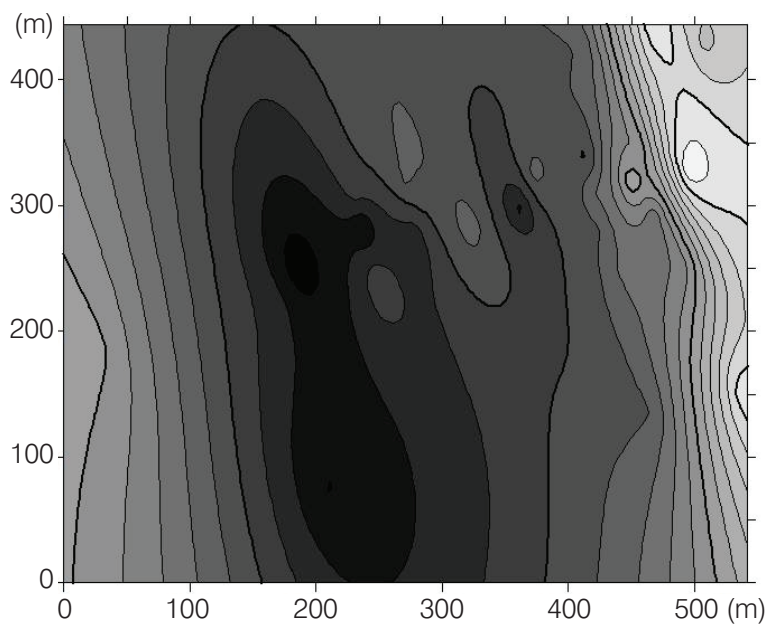

(a)

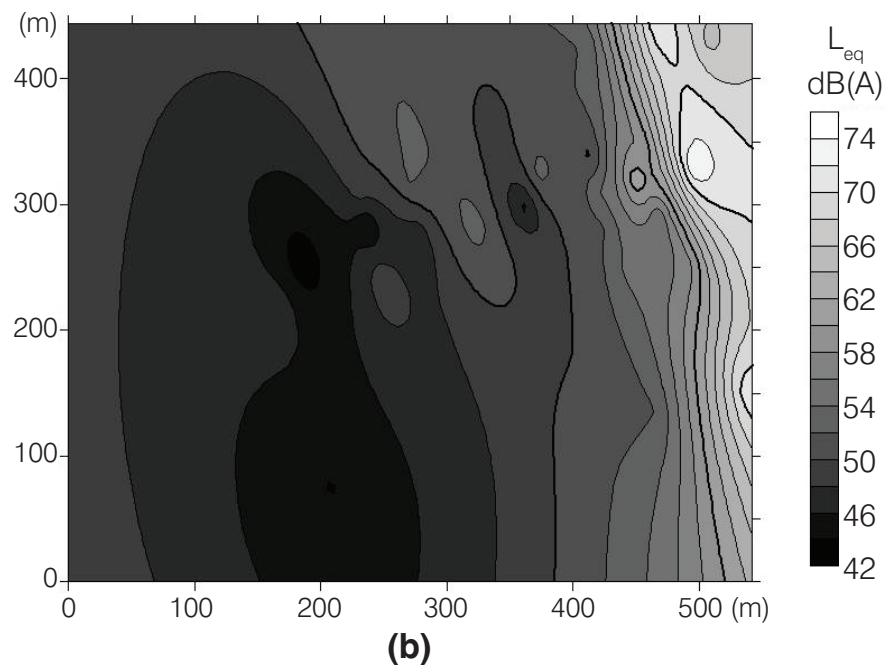

(b)

Figura 5 - Mapas de contorno da situação B gerados pelo modelo esférico considerando o ponto com interferência de quero-quero (a) e sem considerar o mesmo ponto (b).

Com a amostra da situação B também foram construídos semivariogramas nos modelos esférico, exponencial e gaussiano. Além dos mapas gerados a partir desses semivariogramas, analisou-se o mapa feito pelo modelo padrão (default) do software. A melhor modelagem observada, considerando a realidade de campo e a validação cruzada, foi atingida pelo modelo esférico, cujo mapa de contorno pode ser visualizado na Figura 5.

A maior emissão de ruídos foi proveniente do tráfego na avenida, situada à borda direita dos mapas. Na Figura 5 a observa-se que determinada região à esquerda apresentou $\mathrm{L}_{\text {eq }}$ em torno de 60 dB(A). Este nível foi provocado por pássaros da espécie quero-quero que se sentiram ameaçados quando os pesquisadores estavam no ponto de avaliação escolhido, e por isso emitiam seu som característico em grande intensidade. Contudo, como pode ser visto na Figura 5b, o valor não interferiu na distribuição espacial dos valores de $\mathrm{L}_{\text {eq }}$ nas proximidades dos pavilhões das indústrias ou da avenida, que se situam à direita da abcissa $200 \mathrm{~m}$.

A energia gerada por fontes sonoras sofre atenuação ao se propagar em ar livre, devido à distância percorrida, barreiras, absorção atmosférica, vegetação, variação de temperatura e efeito do vento (GERGES, 2000). In situ, naturalmente se percebeu a diferença de intensidade sonora dentro das edificações que contêm as fontes sonoras e no exterior delas. As paredes, teto e demais superfícies agem como barreiras à propagação do som para o ambiente externo. Contudo, no interior da construção seu efeito pode ser aumentado pela reflexão e difração das ondas sonoras.

$\mathrm{Na}$ área externa, pode-se observar (em campo e nos mapas de ruído) que os muros são capazes de reduzir a energia das ondas sonoras a se propagar, e que as barreiras antrópicas (muros, paredes) são mais eficazes na redução de ruído que as naturais presentes na área de estudo, até mesmo porque a vegetação na área não é densa, fechada. Predomina a pastagem e, em algumas áreas, há árvores de grande porte, porém, bastante espaçadas. Apesar da vegetação fornecer pouca atenuação de ruído, pode servir como isolador visual do receptor, apresentando efeito psicológico favorável (GERGES, 2000).

A avaliação quantitativa dos níveis de pressão sonora, em especial nos ambientes de trabalho, é de extrema importância, ao passo que demonstra a presença e a magnitude do risco físico ruído, contribuindo para a escolha dos melhores meios de controle.

Quando o som tem níveis semelhantes aos da voz humana e é emitido nas frequências da voz, causa um "mascaramento", que pode atrapalhar a execução de trabalhos dependentes da comunicação oral, ou dificultar a audição da voz de comando ou de aviso, podendo ser considerado um fator que aumenta a probabilidade de acidentes (ASTETE et al., 1989; STELLMAN; DAUM, 1975).

Outros efeitos do ruído, de acordo com sua intensidade e tempo de exposição, destacam-se: irritação, perturbação do sono, insônia, dificuldade de concentração, ansiedade, estresse, problemas cardiovasculares, dilatação das pupilas, aumento da produção de hormônio da tireoide e de adrenalina, reações musculares, redução da capacidade auditiva e, até, surdez (DERISIO, 2000; MOTA, 2006).

Os consequentes danos à saúde dependem de fatores como: intensidade (quanto mais alta, mais danosa); faixa de frequência (quanto mais elevada, maior o dano); período de exposição (pessoas que permanecem muito tempo expostas a ruídos sofrem mais os seus 
efeitos); intermitência ou continuidade (ruídos contínuos prejudicam a audição; ruídos intermitentes interferem no sistema nervoso; esses efeitos podem ocorrer em conjunto); características de cada indivíduo (susceptibilidade; lesões anteriores no aparelho auditivo) (MOTA, 2006).

O que muitas pessoas não percebem é que são os níveis de ruídos moderados os responsáveis pela maior parte dos problemas auditivos. Isso porque eles, embora possam ser percebidos, são toleráveis e aparentemente adaptáveis pela audição humana, devido ao ritmo agitado da vida moderna (NASCIMENTO et al., 2007).

O processo produtivo dos materiais plásticos se inicia com a segregação e classificação da matéria-prima, etapa na qual o ruído local fica em torno de $78 \mathrm{~dB}(\mathrm{~A})$ no início da esteira transportadora e aumenta no sentido do fluxo da mesma, chegando a atingir $89 \mathrm{~dB}(\mathrm{~A})$.

Após essa etapa, o material é triturado em um moinho, processo que gera ruídos elevados, da ordem de $96 \mathrm{~dB}(\mathrm{~A})$. Em seguida, o plástico triturado passa em tanque de água para limpeza e é, então, conduzido ao secador, ficando armazenado em depósito até ser levado ao aglutinador, local em que se registra ruído de 90 dB(A).

O plástico aglutinado é colocado na extrusora, onde é fundido e recortado na forma de grânulos. Estes são ensacados e transportados para outro pavilhão, no qual passarão por outras extrusoras, dando continuidade ao processo. A área onde ficam concentradas as extrusoras para fabricação de sacos apresenta níveis de pressão sonora de aproximadamente $83 \mathrm{~dB}(\mathrm{~A})$. Já a máquina responsável pela fabricação de mangueiras gera ruído de $87 \mathrm{~dB}(\mathrm{~A})$. No processo de fabricação de tubos de esgoto também são necessárias extrusoras, as quais geram ruído em torno de $82 \mathrm{~dB}(\mathrm{~A})$.

A fabricação de tintas emite ruídos de menor intensidade que os relatados até o momento, referentes ao processamento do plástico. Próximo aos misturadores de tintas o som pode chegar a $78 \mathrm{~dB}(\mathrm{~A})$.

Aspecto importante a se considerar é o efeito do tráfego de veículos na avenida que passa em frente às propriedades estudadas. Carros de passeio, em geral, atingem níveis de $80 \mathrm{~dB}(\mathrm{~A})$, caminhões e ônibus contribuem mais ainda para a poluição sonora, apresentando ruído de 90 dB(A), em média. Contudo, o maior valor instantâneo observado durante o período de coleta de dados foi de $101 \mathrm{~dB}(\mathrm{~A})$, ocasionado por uma moto em alta velocidade.

No zoneamento do município, a área de estudo pertence a uma zona de transição e a avenida em frente é considerada corredor de uso múltiplo. Ambas as categorias devem obedecer aos mesmos limites máximos permissíveis de ruído determinados para Campo Grande, estabelecidos na Lei Complementar no 08/1996: 65 dB(A) no período diurno, $60 \mathrm{~dB}(\mathrm{~A})$ no período vespertino e $55 \mathrm{~dB}(\mathrm{~A})$ no período noturno (PMCG, 1996). Neste trabalho foi avaliado somente o período diurno, e as regiões que ultrapassaram os limites estabelecidos na Legislação Municipal encontram-se destacadas na Figura 6.

De acordo com a Figura 6, na situação A, a residência 2 não foi afetada por níveis de ruído acima do limite estabelecido pela legislação municipal para o período diurno. Enquanto que a residência 1

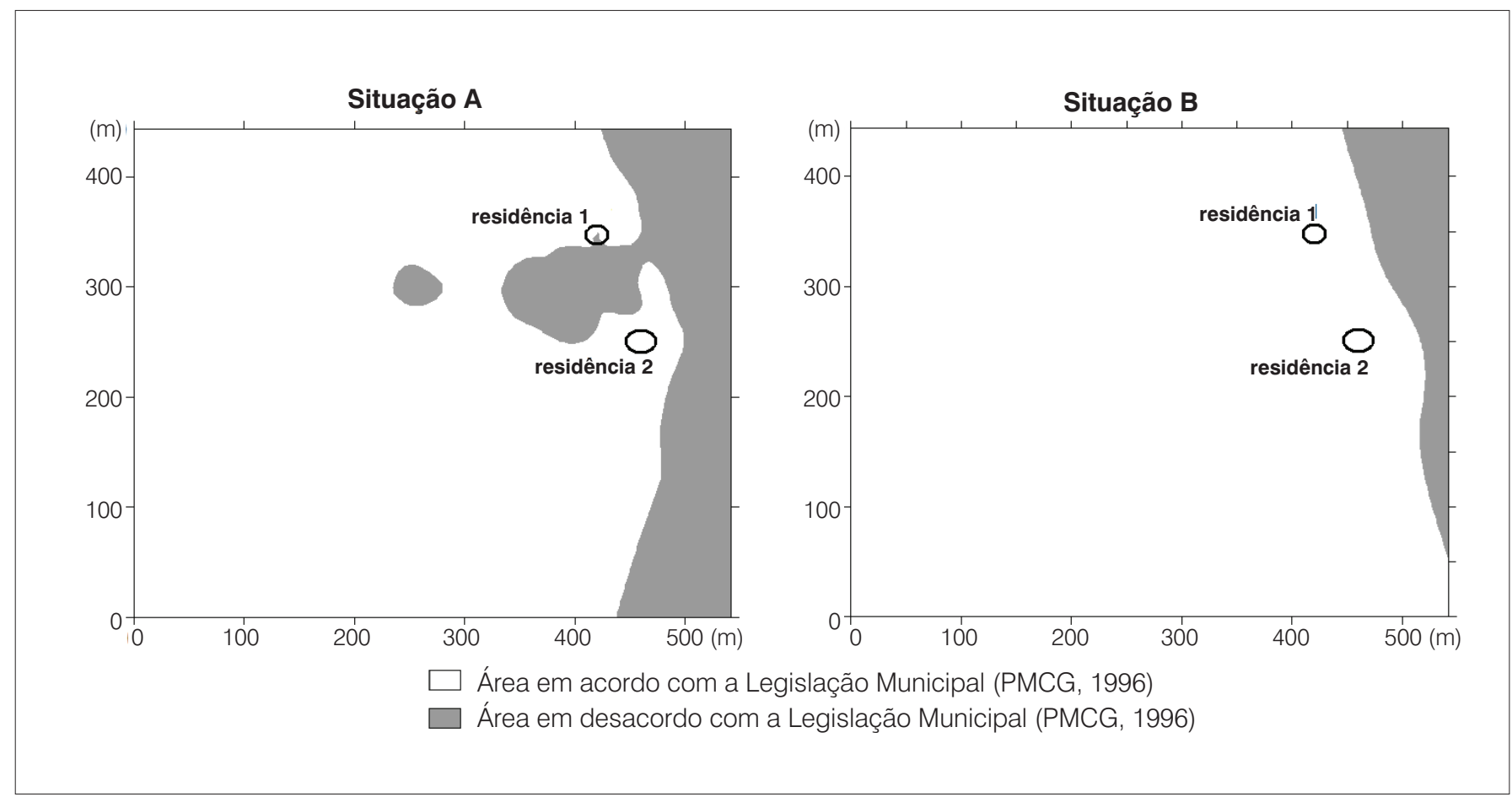

Figura 6 - Áreas em desacordo com a legislação municipal nas situações A e B e localização das residências existentes na abrangência da área de estudo (1 e 2). 
teve parte de sua área acima do referido limite. No final de semana (situação B), o limite foi ultrapassado apenas na avenida e em suas margens. Pela comparação entre as duas situações expostas, pode-se perceber claramente a área de influência da avenida e a ocasionada pelo funcionamento das indústrias. O alargamento da faixa ao Sul, na situação A, pode ter sido provocado pela ausência de pontos de amostragem fora da propriedade.

Para avaliar os limites de exposição ao ruído nos ambientes de trabalho, consideraram-se as exigências do Ministério do Trabalho e Emprego (MTE), em suas Normas Regulamentadoras (NRs). De acordo com a NR 15, para uma exposição diária de 8 horas, o limite de tolerância para ruído contínuo ou intermitente é de $85 \mathrm{~dB}(\mathrm{~A})$, sendo que a cada acréscimo de $5 \mathrm{~dB}(\mathrm{~A})$ reduz-se pela metade o tempo de exposição permitido. Por exemplo, o limite para 90 dB(A) é de 4 horas diárias, e para $100 \mathrm{~dB}(\mathrm{~A})$ apenas 2 horas. Contudo, a NR 9, que trata sobre o Programa de Prevenção de Riscos Ambientais (PPRA), determina que ações preventivas sejam tomadas a partir do nível de ação, que no caso do ruído corresponde ao nível de 80 dB(A) (MTE, 2009).

Outra norma do MTE que faz referência ao agente físico ruído é a NR 17, sobre Ergonomia. O nível de ruído aceitável para efeito de conforto em locais de trabalho onde são executadas atividades que exijam solicitação intelectual e atenção constantes, tais como salas de controle, laboratórios, escritórios, salas de desenvolvimento ou análise de projetos, é de até 65 dB(A) (MTE, 2009).

As regiões da área de estudo em que há exigência de se adotar medidas preventivas ou reduzir a exposição máxima ao ruído encontram-se destacadas na Figura 7. Os maiores valores de pressão sonora concentram-se nas proximidades do moinho, mas praticamente toda a área do pavilhão onde o mesmo está instalado supera os $80 \mathrm{~dB}(\mathrm{~A})$ do nível de ação, obrigando a adoção de medidas preventivas.

Para se proteger contra danos à saúde, deve-se efetuar o controle do ruído. Com este objetivo, procura-se agir primeiramente na fonte, reduzindo a vibração das máquinas e equipamentos, por exemplo. Se mesmo assim não for atingido o grau de atenuação desejado, deve-se intervir no percurso entre a fonte e o receptor, por meio da aplicação de materiais absorventes no ambiente, confinamento da fonte ou colocação de barreiras para dispersar o ruído. Em terceiro lugar vem o controle no receptor, pelo uso de Equipamento de Proteção Individual (EPI) adequado. No entanto, até que sejam adotadas medidas de controle na fonte ou no percurso, deve-se colocar em prática a proteção individual do trabalhador (DERISIO, 2000; TORREIRA, 1999).

Enquanto os níveis de ruído medidos nesta pesquisa permanecerem, quem trabalha no pavilhão de preparação de matéria-prima deverá utilizar protetores auriculares com capacidade de atenuação suficiente para que o nível de pressão sonora no ouvido do receptor seja de no máximo $80 \mathrm{~dB}(\mathrm{~A})$ durante toda a jornada de trabalho.

\section{Conclusões}

Este trabalho demonstrou que é possível elaborar mapas de ruído por meio da aplicação de geotecnologias. A geoestatística é uma poderosa ferramenta para tratar as variáveis regionalizadas, mas os

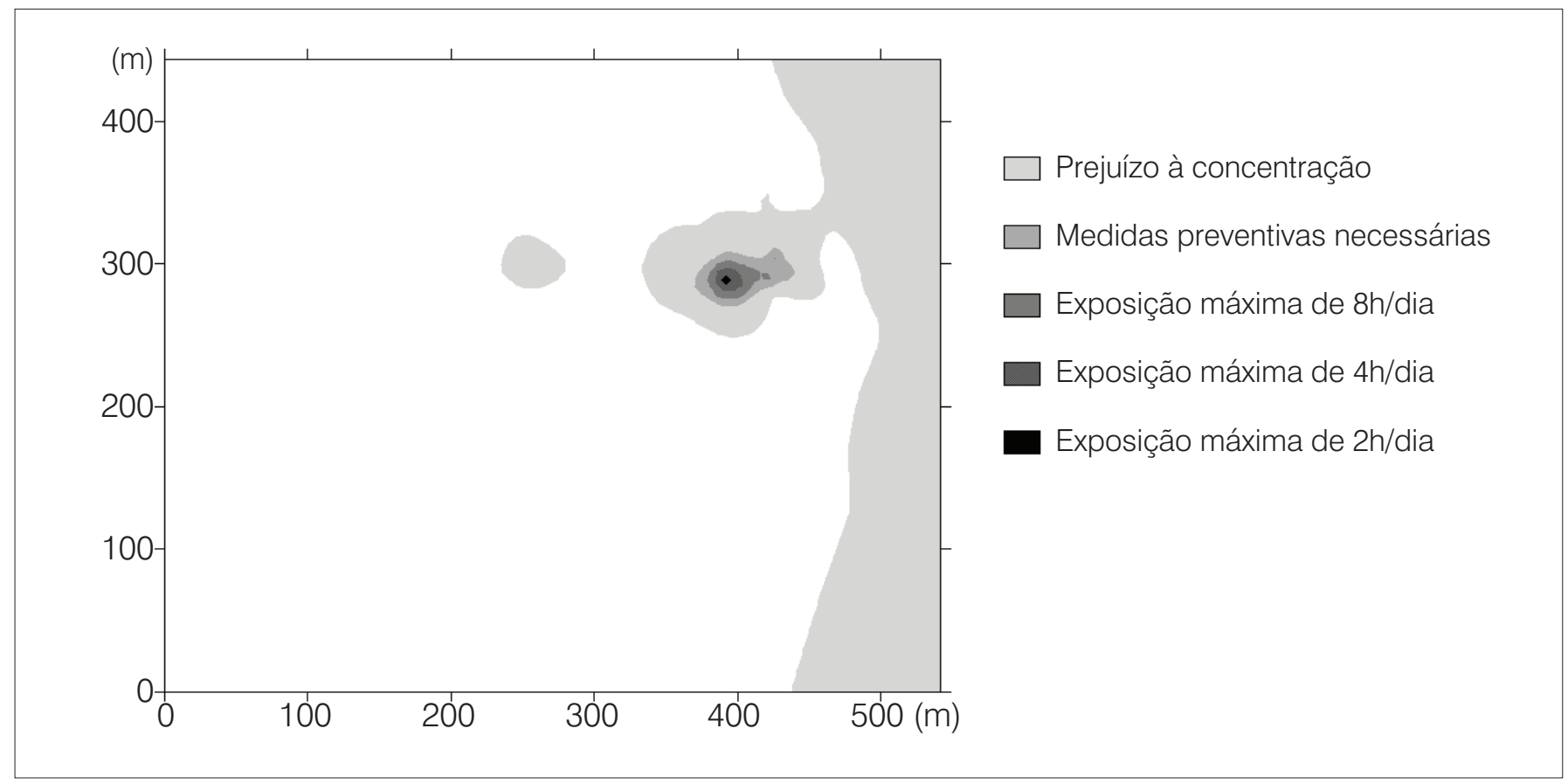

Figura 7 - Interpretação dos resultados de acordo com NR 9, NR 15 e NR 17 (MTE, 2009). 
resultados obtidos devem ser julgados tendo-se em mente as características próprias da variável em estudo e a realidade de campo.

Os mapas de ruído calculam os valores entre os pontos amostrados e proporcionam melhor visualização e entendimento da intensidade, distribuição e propagação do ruído em uma dada área. Sobrepondo os mapas à imagem aérea ortorretificada do local, é possível correlacionar o comportamento espacial do som à existência de barreiras naturais ou artificiais, bem como localizar as áreas mais críticas e identificar as principais fontes de ruído.

Todos os modelos analisados neste estudo foram capazes de indicar as áreas mais críticas quanto ao aspecto ruído, porém, para a amostra A, somente o modelo padrão do software representou os ruídos da avenida de forma contínua ao longo da mesma.

O modelo padrão (default) do Surfer 8 (GOLDEN SOFTWARE, 2002), apesar de não aplicar a análise semivariográfica, também pode produzir resultados satisfatórios, desde que a amostra seja composta de pontos a distâncias capazes de caracterizar o comportamento da variável no local. Em se tratando da propagação do ruído, se o meio não é homogêneo, é importante coletar dados nas proximidades das barreiras de som, pois na presença delas ocorrerá maior variação nos níveis de ruído em menor distância do que o esperado.

Embora o default do software tenha sido considerado o melhor modelo para uma das amostras deste trabalho, o mesmo deve sempre ser utilizado com cautela, pois se a quantidade de pontos e sua distribuição no espaço não forem adequadas, não se conseguirá obter bons resultados.

Independentemente do modelo escolhido, devem-se coletar dados da variável em estudo além dos limites territoriais em que se quer mapear para detectar possíveis interferências externas, visto que a krigagem consegue interpolar bem, mas pode gerar informações menos confiáveis fora da área de coleta de dados.

Os mapas desenvolvidos auxiliaram a delimitar as regiões nas quais os níveis de ruído ultrapassam os limites estabelecidos e onde medidas de controle devem ser adotadas. Os maiores níveis de ruído são gerados na etapa de preparação da matéria-prima plástica e se concentram na área entre o moinho e o aglutinador. Nos pavilhões da indústria de tintas não são atingidos os limites de tolerância estabelecidos pelo Ministério do Trabalho.

O trânsito contribui bastante para o aumento dos níveis sonoros. Apesar de o som produzido por cada veículo logo se perder no espaço após sua passagem, a via é bastante movimentada, havendo sempre veículos transitando nela e emitindo ruídos.

Por fim, este estudo reforça a importância de se respeitar o zoneamento urbano para que as indústrias fiquem situadas distante de zonas residenciais, hospitais, escolas e outros estabelecimentos de usos sensíveis ao ruído.

\section{Referências}

ABNT - ASSOCIAÇÃO BRASILEIRA DE NORMAS TÉCNICAS. (2000) NBR 10151: Acústica - Avaliação do ruído em áreas habitadas, visando o conforto da comunidade - Procedimento. Rio de Janeiro.

ASTETE, M.W.; GIAMPAOLI, E.; ZIDAN, L.N. (1989) Riscos físicos. São Paulo: Fundacentro.

DAVIS, M.L; CORNWELL, D.A. (1998) Introduction to environmental engineering. 3rd ed. Boston. McGraw-Hill.

DERISIO, J.C. (2000) Introdução ao controle de poluição ambiental. 2 ed. São Paulo. Signus.

GERGES, S.N.Y. Ruído: fundamentos e controle. 2 ed. Florianópolis. NR, $670 \mathrm{p}, 2000$.

GOLDEN SOFTWARE INC. (2002) Surfer. Surface Mapping System, Version 8.01. Golden Software. CD-ROM.

LANDIM, P.M.B. (2003) Análise estatística de dados geológicos. 2 ed. São Paulo: UNESP.
LEÃO, R.N.; DIAS, F.A.M. (2010) Perfil audiométrico de indivíduos expostos ao ruído atendidos no núcleo de saúde ocupacional de um hospital do município de Montes Claros, Minas Gerais. Revista CEFAC, v. 12, n. 2 .

MOTA, S. (2006) Introdução à Engenharia Ambiental. 4 ed. Rio de Janeiro. ABES.

MTE - MINISTÉRIO DO TRABALHO E EMPREGO. (2009) Segurança e medicina do trabalho. 63 ed. São Paulo. Atlas.

NASCIMENTO, R.G.; GODOY, R.M.B; SOUTO JUNIOR, C.A.; UEHARA G.T. (2007) Avaliação da Poluição Sonora na UNICAMP. Revista Ciências do Ambiente On-Line, v. 3, n. 1, p. 59-65.

PMCG - PREFEITURA MUNICIPAL DE CAMPO GRANDE. Lei Complementar n. 08, de 28 de março de 1996. Altera Dispositivos da Lei n 2.909, de 28 de julho de 1992 - Código de Polícia Administrativa do Município de Campo Grande-MS, e dá outras providências. Campo Grande, 1996 
SANTOS, L.C.; VALADO, F. (2004) O mapa de ruído municipal como ferramenta de planeamento. Acústica 2004. Portugal.

SANTOS, L.C.; VALÉRIO, P. (2004) O mapa de ruído como ferramenta de gestão ambiental na indústria. Acústica 2004. Portugal.

SHAFER, R.M. (2001) A afinação do mundo. Trad. Marisa Trench Fonterrada. São Paulo: UNESP.
SHAFER, R.M. (2000) O ouvido pensante. 2 ed. São Paulo: UNESP.

STELLMAN, J.M.; DAUM, S.M. (1975) Trabalho e saúde na indústria: riscos físicos e químicos e prevenção de acidentes. v. 1. São Paulo: EDUSP.

TORREIRA, R.P. (1999) Manual de segurança industrial. São Paulo: Margus. 